\title{
The purification of reduced $\beta 2$-glycoprotein I showed its native activity in vitro
}

\author{
Saijun Zhou, Ming Lu, Jiantong Zhao, Shuaihui Liu, Xin Li, Rui Zhang, Hongyan Liu and Pei Yu (D)
}

\begin{abstract}
Background: New evidence has shown that reduced $\beta 2$-glycoprotein I ( $\beta 2 \mathrm{GPI}$ ) has anti-oxidative stress and anti-inflammatory activity. However, the details are still poorly understood. This study aims to prepare stable reduced $\beta 2 \mathrm{GPI}$ with its native bioactivity in vitro.
\end{abstract}

Methods: Human $\beta 2$ GPI was purified from plasma first with perchloric acid precipitation and then purified with a series of chromatography methods including Sephadex G-25 desalting, SP HP, AF-heparin HC-650 M, and Sephacryl S-200. The purified human $\beta 2$ GPI was reduced with thioredoxin-1 (TRX-1) activated by DL-dithiothreitol (DTT). Glutathione (GSH) was selected to block the free thiols in reduced $\beta 2$ GPI. LC/MS was used to verify the location of free thiols. Western blot analysis was used to detect $\beta 2$ GPI immunoreactivity. MTS and flow cytometry were conducted to investigate its biological effect on oxidative-stress-induced death of human umbilical vein endothelial cells (HUVECS). The levels of tumour necrosis factor-alpha (TNF-a),interleukin-6 (IL-6) interleukin-10 (IL-10), interleukin-12P70 (IL-12P70), interferon-gamma (IFN- $\gamma$ ) and monocyte chemoattractant protein -1(MCP-1) in mouse serum were quantified to assess its anti-inflammatory activity in lipopolysaccharide (LPS)-mediated systemic inflammation.

Results: We obtained approximately $10 \mathrm{mg} \beta 2 \mathrm{GPI}$ (purity 98.7\%) from $200 \mathrm{ml}$ plasma. The protein yield was 0. $05 \mathrm{mg} / \mathrm{ml}$ plasma. $\beta 2 \mathrm{GPI}$ was then reduced by TRX-1/DTT in vitro; the free thiols were detected on Cys 288 and Cys326 in domain $V$ of $\beta 2 \mathrm{GPI}$. The GSH blockage stabilized the reduced $\beta 2 \mathrm{GPI}$ in vitro. This reduced $\beta 2 \mathrm{GPI}$ can be recognized by the anti- $\beta 2 \mathrm{GPI}$ antibody, can significantly reduce the death of HUVECS after $\mathrm{H}_{2} \mathrm{O}_{2}$ treatment and can significantly decrease the levels of TNF- - , IL-6,IFN- $\gamma$ and MCP-1 in mice upon LPS stimulation.

Conclusion: Stable reduced $\beta 2 \mathrm{GPI}$ can be obtained in vitro by TRX-1 deoxidation followed by the blockage of thiols with GSH. This reduced $\beta 2 \mathrm{GPI}$ maintains the same immunological activity as oxidized $\beta 2 \mathrm{GPI}$ and has the ability to counter the oxidative stress induced by $\mathrm{H}_{2} \mathrm{O}_{2}$ in HUVECs and inflammation in LPS-mediated inflammation in mice.

Keywords: $\beta 2$-glycoprotein I, Reduced $\beta 2$-glycoprotein I, Thioredoxin-1, GSH, Diabetic vascular disease, Oxidative stress

\section{Background}

$\beta 2$-glycoprotein I ( $\beta 2 \mathrm{GPI})$, which is also known as apolipoprotein $\mathrm{H}$, is a phospholipid-binding plasma protein that circulates at a concentration of approximately $4 \mu \mathrm{M}$. $\beta 2 \mathrm{GPI}$ is well known as the major antigen of antiphospholipid syndrome and has a dual function as a procoagulant and anticoagulant $[1,2]$. Recent studies have shown that $\beta 2 \mathrm{GPI}$ could also play a role in vascular disease [3-6] as well as the innate immune response [7-9].

\footnotetext{
*Correspondence: yupei@tmu.edu.cn

Key Laboratory of Hormones and Development (Ministry of Health), Tianjin Key Laboratory of Metabolic Diseases, Tianjin Metabolic Diseases Hospital and Tianjin Institute of Endocrinology, Tianjin Medical University, Tianjin 300070, China
}

32GPI is composed of five domains and four glycosylation sites connected to its $\mathrm{N}$ terminus with a "hook-like" crystal structure [1]. Domains I to IV each have two disulfide bridges, whereas domain $\mathrm{V}$ has three disulfide bridges, including a disulfide bridge that incorporates a Cterminal cysteine [1]. Domain V also contains a positively charged lysine-rich region and a hydrophobic flexible loop segment, and both of these regions are required for the binding of $\beta 2 \mathrm{GPI}$ to negatively charged macromolecules [1]. The disulfide bond in domain $\mathrm{V}$ is susceptible to cleavage by the oxidoreductases thioredoxin-1 (TRX-1) and protein disulfide isomerase (PDI), leading to the generation of free thiols at Cys288 and Cys326 [3, 10, 11]. 
This special form of $\beta 2$ GPI is called reduced $\beta 2$ GPI. Therefore, $\beta 2$ GPI exists in two forms (reduced $\beta 2$ GPI and oxidized $\beta 2 \mathrm{GPI}$ ) in plasma, and the main form of $\beta 2$ GPI in plasma is the free thiol form [10]. In recent years, reduced $\beta 2$ GPI was found to have distinct functions from the oxidized $\beta 2 \mathrm{GPI}[3,4,9]$. Reduced $\beta 2 \mathrm{GPI}$ has been shown to play a protective role against oxidative stress-induced vascular endothelial cell death, indicating that it has an anti-oxidative stress function. Its anti-oxidative stress function was further confirmed in age-related macular degeneration in patients [12] and hypoxia-induced retinal angiogenesis in mice [13]. Reduced $\beta 2$ GPI was also found to inhibit macrophage foam cell formation that is induced by oxidized low density lipoprotein (ox-LDL) [4] in vitro and to inhibit vascular lipid deposition and plaque formation by reducing the expression of matrix metalloproteinases/tissue inhibitors of metalloproteinases (MMPs/TIMPs) via the downregulation of the p38 mitogen-activated protein kinase (p38 MAPK) signalling pathway in vivo [14], which suggests that reduced $\beta 2$ GPI may alleviate vascular lipid toxicity through an anti-inflammatory mechanism. This anti-inflammatory activity was recently confirmed by our previous study in LPS-mediated systemic inflammation in mice [9].

However, the anti-inflammatory mechanism of the reduced $\beta 2$ GPI is still poorly understood. Although a large proportion of plasma $\beta 2$ GPI exists in free thiol form, this form is unstable in vitro [3]. Until now, the preparation of stable reduced $\beta 2 \mathrm{GPI}$, whether by isolating the $\beta 2 \mathrm{GPI}$ from the plasma or by recombinant methods, has not been reported. Therefore, it is important to obtain a stable product in vitro to understand this special form of $\beta 2$ GPI.

In this study, we prepared stable reduced $\beta 2 \mathrm{GPI}$ in vitro by a deoxidation reaction and the thiol blockage method and investigated its effect on the oxidative stress-induced death of human umbilical vein endothelial cells (HUVECs) and its anti-inflammatory activity in LPS-mediated systemic inflammation in mice.

\section{Methods}

\section{Materials}

Human plasma was acquired from the Tianjin Blood Centre. The Sephadex G-25 desalting column, SP HP column, AF-heparin HC-650 M column, and Sephacryl S-200 column were purchased from GE Healthcare (USA). Reduced L-glutathione, dithiothreitol, and Nethylmaleimide were purchased from Sigma (Saint Louis, MO). Recombinant TRX-1 was purchased from $R \& D$ Corporation (Minneapolis, MN). The CellTiter 96 AQueous One Solution Cell Proliferation Assay Kit was purchased from BD Biosciences (Franklin Lakes, NJ). Annexin V-FLUOS staining kit was purchased from Roche (Penzberg, Germany). The other materials were purchased from The Tianjin Ruentex Science and Technology Development Co. Ltd. LPS from E. coli, (serotype 0111:B4) was purchased from Sigma (Sigma-Aldrich Inc., St. Louis, MO). Male C57BL/6 J mice (6 to 8 weeks old) were obtained from the Experimental Animal Center of Peking University Health Science (Beijing, China). Mouse IL- 6 and TNF- $\alpha$ ELISA kits were purchased from Sangon Biological Engineering Technology and Services Co., LTD (Shanghai, China). Human plasma was purchased from the Tianjin Municipal Blood Center (Tianjin, China). Rabbit anti-human $\beta 2$ GPI monoclonal antibody was purchased from Abcam (London, UK). Goat antirabbit polyclonal antibody was purchased from Bioworld Technology, Inc. (St. Louis, MO, USA). This study was approved by the Animal Ethics Committee of the Metabolism Disease Hospital of Tianjin Medical University.

\section{Human plasma precipitation and sample desalting}

Human plasma was mixed with perchloric acid (70\% volume fraction) at a volume ratio of 1:40, stirred for $30 \mathrm{~min}$ at $4{ }^{\circ} \mathrm{C}$ and then centrifuged at $1000 \mathrm{rpm}$ at $4{ }^{\circ} \mathrm{C}$ to recover the supernatant. The supernatant was reserved, and the $\mathrm{pH}$ was titrated to 8.0 with a saturated $\mathrm{Na}_{2} \mathrm{CO}_{3}$ solution.

The cleared supernatant $(170 \mathrm{ml})$ was loaded onto a desalting buffer $(50 \mathrm{mM}$ acetate $\mathrm{pH}$ 5.2)-preequilibrated G-25 desalting column $(\mathrm{XK} 50 \times 20$ with $17 \mathrm{~cm}$ column height, GE Healthcare, USA) at a flow rate of $20 \mathrm{ml} /$ min. A total of $180 \mathrm{ml}$ of the sample was collected in this step, and the sample was then purified with an SP HP column.

Briefly, the desalted sample was loaded onto a preequilibrated HiTrap SP HP (GE Healthcare, USA) at a flow rate of $3 \mathrm{ml} / \mathrm{min}$ in buffer A (50 mM acetate $\mathrm{pH} 5.2)$. The column was then washed with buffer A for 2 column volumes (CV), 2\% buffer B (50 mM acetate $\mathrm{pH} 5.2,1 \mathrm{M}$ $\mathrm{NaCl})$ for $5 \mathrm{CV}$ and eluted with a gradient of $5 \%-50 \%$ buffer B for $20 \mathrm{CV}$, and $50 \%-100 \%$ buffer B for $5 \mathrm{CV}$, and then the elution gradient was switched to $100 \%$ buffer B for $5 \mathrm{CV}$. The $\beta 2 \mathrm{GPI}$ standard sample and protein fractions of every tube were used for SDS-PAGE. According to SDS-PAGE, the protein fractions with a band showed the same profiles as the standard sample. Some samples of mixed proteins were digested with trypsin PNGase $\mathrm{F}$ and analysed by LC/MS to verify $\beta 2 \mathrm{GPI}$-positive fractions. LC/MS analysis was conducted as previously described $[13,14]$. Fractions containing $\beta 2$ GPI were pooled together for AF-heparin HC-650 M column purification.

\section{AF-heparin HC-650 M column purification}

An AF-heparin HC-650 M column (Tricorn $10 \times 10$ with $9 \mathrm{~cm}$ column height, USA; the medium-sized column was purchased from TOSHH) was used for the 
middle purification step. After the column was equilibrated with equilibration buffer ( $20 \mathrm{mM}$ Tris 8.0$)$, the pooled samples from the SP HP step were loaded onto the AF-heparin HC-650 M column and washed with buffer A for 2 column volumes (CV), 20\% buffer B (50 mM acetate $\mathrm{pH} 5.2,1 \mathrm{M} \mathrm{NaCl}$ ) for $5 \mathrm{CV}, 30 \%$ buffer $\mathrm{B}(50 \mathrm{mM}$ acetate $1 \mathrm{M} \mathrm{NaCl} \mathrm{pH} \mathrm{5.2)} \mathrm{for} 5 \mathrm{CV}$, eluted with a gradient of $30 \%-80 \%$ buffer B for $20 \mathrm{CV}$, and then the elution gradient was switched to $100 \%$ buffer $\mathrm{B}$ for $5 \mathrm{CV}$. The fractions were then collected and analysed by SDS-PAGE. The fractions containing the same profile as the standard sample were pooled together.

\section{Protein clean-up with the S-200 column}

Fractions containing the target protein from the last step were concentrated by an Amicon Ultra- $15 \mathrm{ml}$ concentrator (10 kDa Centrifugal Filter Unit, Merck-Millipore) to $5 \mathrm{ml}$ and then loaded onto a Superdex-200 column (HiLoad 16/ 60 Superdex 200 prep grade, GE) that was preequilibrated with equilibration buffer $(20 \mathrm{mM} \mathrm{PB}, 0.15 \mathrm{M} \mathrm{NaCl}, 10 \%$ glycerol $\mathrm{pH}$ 7.2). The fractions collected in this step were also analysed by SDS-PAGE. N-glycosylation was verified by the PNGase F enzyme digestion method [15].

\section{Preparation of reduced $\beta 2$ GPI and blockage method development}

(a) The following solutions were mixed together: $420 \mu \mathrm{l}$ HBS buffer solution, $40 \mu \mathrm{l}$ DTT solution $(20 \mathrm{mM}$ HBS, $1 \mathrm{mM}$ DTT), and $26 \mu \mathrm{l}$ TRX-1 solution $(0.78 \mathrm{mg} / \mathrm{ml})$, and then incubated at $3{ }^{\circ} \mathrm{C}$ for $45 \mathrm{~min}$.

(b) Approximately $45 \mu \mathrm{l} \beta 2 \mathrm{GPI}$ solution $(2 \mathrm{mg} / \mathrm{ml}$ ) was added to $405 \mu \mathrm{l}$ HBS buffer solution, and the mixed solution was shaken by brief centrifugation.

(c) B2GPI-HBS mixed solution was then added to the DTT-TRX-1-HBS solution, and the reaction solution was incubated at $37^{\circ} \mathrm{C}$ for $1 \mathrm{~h}$.

(d)Thereafter, the reaction solution was divided into three aliquots, and iodoacetamide solution $(40 \mathrm{mM})$, GSH solution (40 mM), or HBS buffer solution was separately added to each aliquot. The solution was placed at $4{ }^{\circ} \mathrm{C}$ to end the reduction reaction, and each reaction was analysed by nonreducing SDSPAGE.

To block the free thiol form of $\beta 2$ GPI, cysteamine or GSH was added to the $50 \mu \mathrm{l}$ reaction with final concentrations of 40 and $80 \mathrm{mM}$, respectively. The reaction was then incubated at $37{ }^{\circ} \mathrm{C}$ for either $2 \mathrm{~h}$ or overnight. Aliquots $(2 \mu \mathrm{g})$ of samples from each step and time point were analysed by nonreducing SDS-PAGE.

\section{LC/MS analysis of the free thiol form of $\beta 2 \mathrm{GPI}$}

To develop an LC/MS-based method to analyse the reduced form of $\beta 2 \mathrm{GPI}$, the purified $\beta 2 \mathrm{GPI}$ was pretreated using two different conditions: A) $2 \mu \mathrm{g}$ protein was denatured in $50 \mu \mathrm{l}$ denaturing buffer $(10 \mathrm{mM}$ DTT, $0.1 \%$ RapiGest (Waters Corp.), $50 \mathrm{mM} \mathrm{NH} \mathrm{HCO}_{3}$ ) for $30 \mathrm{~min}$ at $60{ }^{\circ} \mathrm{C}$; B) $2 \mu \mathrm{g}$ protein was denatured as in (A), and iodoacetamide (IAA) was then added to a final concentration of $20 \mathrm{mM}$ and incubated at RT for $30 \mathrm{~min}$ to fully alkylate the reduced cysteine. The samples of the two conditions were enzymatically digested for $4 \mathrm{~h}$ at $37{ }^{\circ} \mathrm{C}$ with trypsin at a $20: 1(\mathrm{w} / \mathrm{w}$, protein:enzyme). Trifluoroacetic acid (TFA) was added to each sample to the final of $0.5 \%$ to stop the enzyme digestion. The clarified samples were used for LC/MS analysis. LC/MS analysis was conducted as previously reported $[16,17]$.

The samples from the TRX reduction and alkylation blockage reactions were digested in $0.1 \%$ RapiGest, $50 \mathrm{mM} \mathrm{NH}_{4} \mathrm{HCO}_{3}$, and the samples from the TRX reduction and GSH reactions were digested with trypsin for $4 \mathrm{~h}$ at $37{ }^{\circ} \mathrm{C}$ at a $20: 1(w / w$, protein:enzyme). Trifluoroacetic acid (TFA) was added to each sample to a final concentration of $0.5 \%$ to stop the enzyme digestion. The clarified samples were used for LC/MS analysis.

\section{Western blot analysis for the immunoreactivity of reduced $\beta 2 \mathrm{GPI}$}

The aliquots ( $5 \mathrm{ng}$ per lane) of the total protein were resolved on a Nu-PAGE TM 4-12\% Bis-Tris gel and blotted onto a nitrocellulose membrane. The membrane was blocked with $2 \%$ BSA in TBST $(20 \mathrm{mM}$ Tris- $\mathrm{HCl}$ $\mathrm{pH}$ 7.6, $137 \mathrm{mM} \mathrm{NaCl}$, and $0.01 \%$ Tween-20) for $1 \mathrm{~h}$ at RT, followed by incubation with anti- $\beta 2$ GPI antibody overnight. After washing with TBST, the membrane was re-probed with HRP-anti-rabbit IgG (1:1000) in 2\% BSA in TBST for $2 \mathrm{~h}$ at RT. After exposure in the darkroom, peroxidase activity on PVDF membranes was visualized on X-ray film with an ultraviolet transmission analyser.

\section{Effect of reduced $\beta 2 \mathrm{GPI}$ on oxidative stress-induced cell death in human endothelial cells}

HUVECs were obtained from freshly delivered umbilical cords after informed consent. Cells were cultured with EGM or M199 plus 20\% FBS ECGP and incubated at $37^{\circ} \mathrm{C}$ in $5 \% \mathrm{CO}_{2}$. Endothelial cells were identified by their typical cobble-stone morphology and by immunostaining with anti-CD31 antibody, as previously described [6]. Experiments were conducted using HUVECs between passages 3 and 4. HUVECs were seeded at a density of $1 \times 10^{5}$ cells $/ \mathrm{mL}$ in 96-well or 24-well plates and grown to confluency over 24-48 h. Cells were grown to confluency and treated with $10 \mathrm{nM}$ $\mathrm{H}_{2} \mathrm{O}_{2}$ as previously described [4]. After overnight incubation in M199/0.1\% FCS, the cells were washed 
twice in M199/0.05\% BSA; then, $1 \mu \mathrm{M}$ of $\beta 2 \mathrm{GPI}$ or reduced $\beta 2$ GPI was added to the medium and cells were incubated at $37{ }^{\circ} \mathrm{C}$ for $30 \mathrm{~min}$. The cells were then transferred to a $1.5 \mathrm{ml}$ Eppendorf tube containing $\mathrm{H}_{2} \mathrm{O}_{2}$ diluted in $\mathrm{HBS}$ to a final concentration of $10 \mathrm{mM}$ and incubated at $37{ }^{\circ} \mathrm{C}$ for $30 \mathrm{~min} . \mathrm{H}_{2} \mathrm{O}_{2}$ was then deactivated with catalase, cells were incubated overnight at $37^{\circ} \mathrm{C}$ with M199/FCS (10\%), and cell viability was quantified with MTS as previously described [6]. To investigate the effect of reduced $\beta 2$ GPI on cell proliferation, we used trypan blue dye to count the number of living cells. The cells were transferred to 24-well plates and overgrew the plates. After the cells were collected, $0.4 \%(w / v)$ trypan blue dye was added, and using a haemocytometer under the optical microscope, the number of living cells ( 3 wells) was counted. Cell apoptosis was assessed using flow cytometry. Cells were digested with trypsin and collected by centrifugation $(2000 \mathrm{rpm}, 5 \mathrm{~min})$. Binding buffer $(500 \mu \mathrm{l})$ was added to cells. Then, $5 \mu \mathrm{l}$ annexin V-FITC and $5 \mu \mathrm{l}$ propidium iodide were added to the binding buffer. Samples were incubated in the dark for $10 \mathrm{~min}$ at RT, and then flow cytometric analysis was performed. The excitation wavelength was $488 \mathrm{~nm}$. The emission wavelength was $530 \mathrm{~nm}$.

\section{Effect of reduced $\beta 2$ GPI on LPS-mediated systemic inflam- mation in mice}

Sixteen male mice in each group were housed in a specific pathogen-free environment, and their health status was regularly monitored. Purified plasma $\beta 2$ GPI $(2 \mu \mathrm{M})$ or reduced $\beta 2$ GPI with $1 \mathrm{nM}$ LPS were preincubated for $15 \mathrm{~min}$ at $37{ }^{\circ} \mathrm{C}$ before injection into mice [7]. Then, male mice were injected with $1 \mu \mathrm{g} / \mathrm{g}$ body weight (gbw) with LPS from E. coli (Sigma-Aldrich) in GSH (80 mM) or the same volume of sterile saline through tail vein. Six hours post-injection, mice were euthanized, and approximately $1 \mathrm{ml}$ of blood was collected by cardiac puncture. Serum was collected by centrifugation of clotted blood at $1500 \mathrm{~g}$ for $10 \mathrm{~min}$ to be used in a cytokine assay. The supernatants were separated, and the levels of IL-6, IL-10, IL-12p70, IFN- $\gamma$, TNF- $\alpha$, and MCP-1 were determined using a cytometric bead array kit for mouse inflammatory cytokines (BD Biosciences) according to the manufacturer's instructions. Briefly, beads with distinct fluorescence intensities are coated with antibodies that specifically react with each of the cytokines and are detected by phycoerythrin-conjugated antibodies, which produces a fluorescent signal in proportion to the amount of bound analyte. The bead populations were mixed together to form the bead array, which was resolved in a FACSAria TM flow cytometer, and the beads were differentiated by their distinct spectral characteristics. Standard curves were determined for each cytokine from 20 to $50,000 \mathrm{pg} /$ $\mathrm{ml}$. The data were acquired on a FACS Aria TM flow cytometer (BD Biosciences) and analysed with FCAP
Array software (Soft Flow Hungary, Kedves, Hungary) by applying the 4-parameter curve fit option.

\section{Statistical analysis}

SPSS 11.5 statistical software was used for data processing and analysis. The values for all measurements are expressed as the mean \pm standard error of the mean. One-way ANOVA was used to evaluate significant differences. All $P$ values were two-sided and were considered statistically significant if they were less than $0.05(P<0.05)$.

\section{Results \\ Production of $\beta 2 \mathrm{GPI}$}

In the SP HP chromatography step, $\beta 2$ GPI was eluted as the second main peak (Fig. 1a). The purity of the pooled peak showed a dramatic increase in purity but still contained several impurities (Fig. 1b). After AFheparin HC-650 $\mathrm{M}$ and gel filtration purification, the sample showed a homogenous peak on the S-200 column (Fig. 1c), and the purity was as good as that of the commercial standard (Fig. 1d). Consistent with reports of $\beta 2 \mathrm{GPI}$ containing several $\mathrm{N}$-glycosylation modifications, the purified protein that was obtained after PNGase $F$ digestion showed smaller bands by SDS-PAGE (lane 3, Fig. 1d). Finally, $10 \mathrm{mg}$ B2GPI was purified from $200 \mathrm{ml}$ human plasma. The purity of $\beta 2$ GPI was approximately $98.7 \%$. The protein yield was $0.05 \mathrm{mg} / \mathrm{ml}$ plasma. The purified protein was digested by trypsin and followed by LC/MS-based peptide mapping to confirm the sequence.

\section{Free thiols in reduced $\beta 2 \mathrm{GPI}$ are induced and blocked by GSH}

In the free cysteine blockage step, two different blockage reagents, cysteamine and GSH, were compared at two different time points $\left(2 \mathrm{~h}\right.$ and overnight at $\left.37{ }^{\circ} \mathrm{C}\right)$. After blockage for $2 \mathrm{~h}$, the MW was slightly different from the native form, but the difference was not obvious (Fig. 2a). After blockage overnight, the target protein disappeared under the cysteamine-blockage condition. In addition, the GSH-blockage condition resulted in an obvious MW increase (Fig. 2b). The reduced and GSH-blocked forms were compared and analysed by both reducing and nonreducing SDS-PAGE. When analysed by reducing SDSPAGE, the native and reduced forms had the same MW; however, when analysed by nonreducing SDS-PAGE, the reduced and blocked forms had a higher MW (Fig. 2c).

Based on the protein sequence and the trypsin theoretical digestion, the information for the target peptide (TDASDVKPC) is described in Fig. 3a. The protein sample after reduction contained only the reduced peptide (Fig. 3b \& c, upper); however, the protein sample after reduction and alkylation exhibited an alkylated peptide 

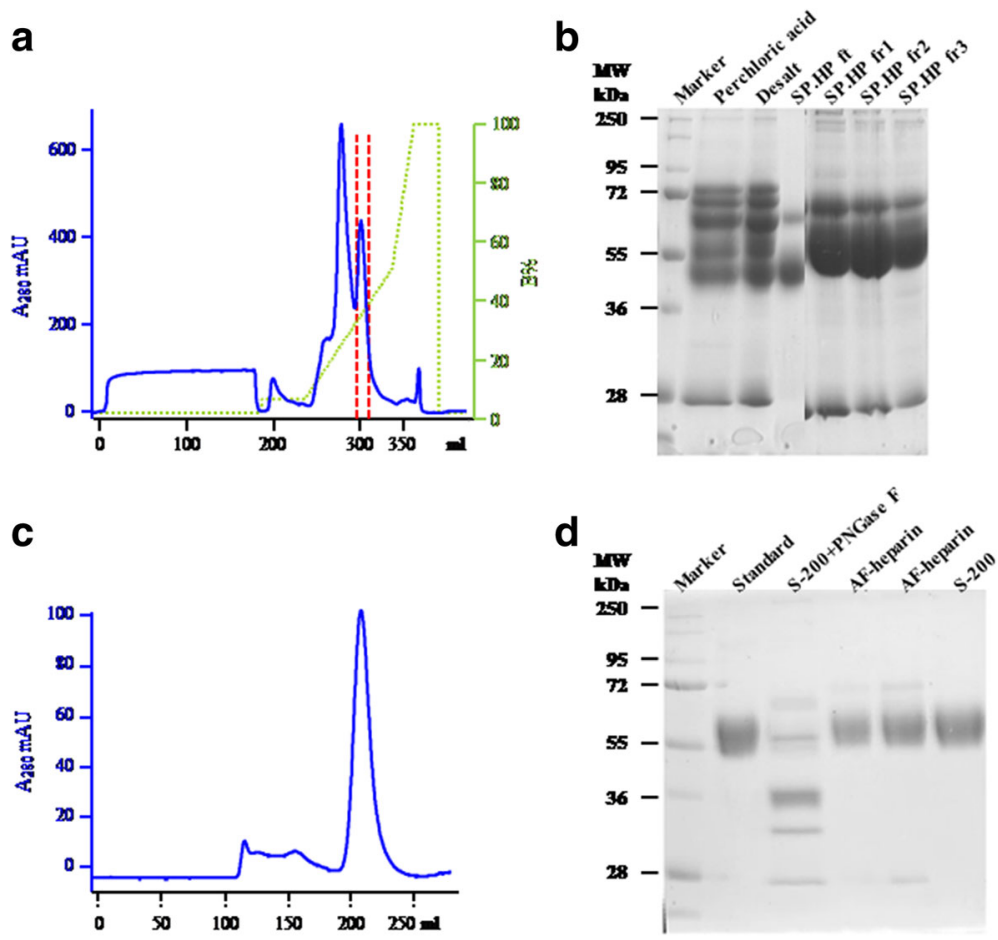

Fig. 1 Purification of $\beta 2$ GPI. Human plasma was treated with perchloric acid, desalted with G-25 column, and purified with a series of chromatography steps on an SP HP column, AF-heparin HC-650 M column, and S-200 column in sequence. After purification with the SP HP column (a), the sample fractions (b) were analysed by SDS-PAGE. Marker: protein standard marker (Bio-Rad cat. 161-0374), perchloric acid: supernatant after perchloric acid precipitation, Desalt: G-25 desalted sample, SP HP ft: the flow-through of SP HP, SP HP fr1-3: the pooled elution fractions of SP HP. After further purification with the AF-heparin HC-650 M column and S-200 column (c), the sample fractions were analysed by SDS-PAGE (d). Marker: protein standard marker (Bio-Rad cat. 161-0374), PNGase F: SP digestion, AF-heparin: fractions of AF-heparin chromatography step, S-200: pooled fractions of S-200 step

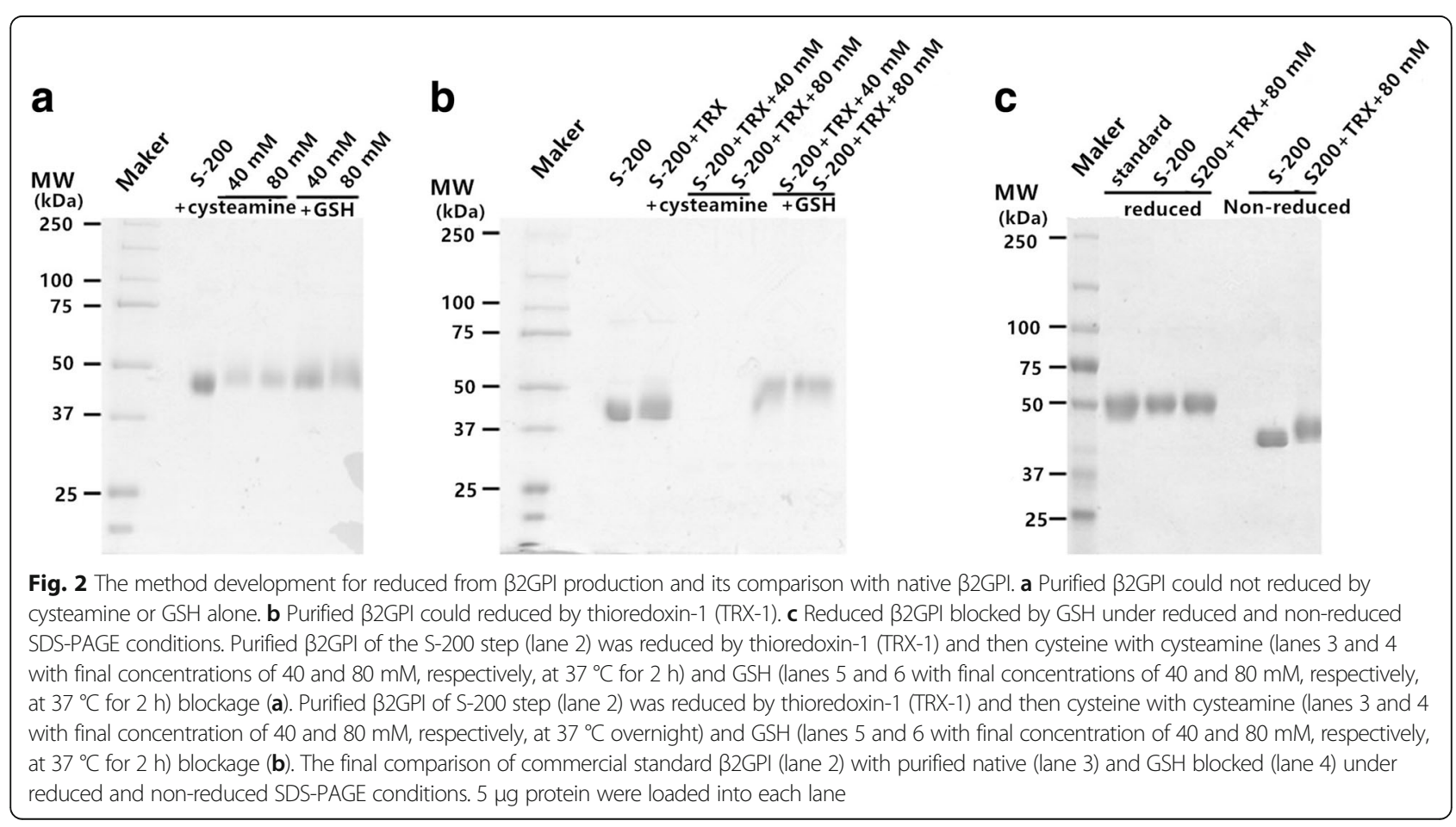



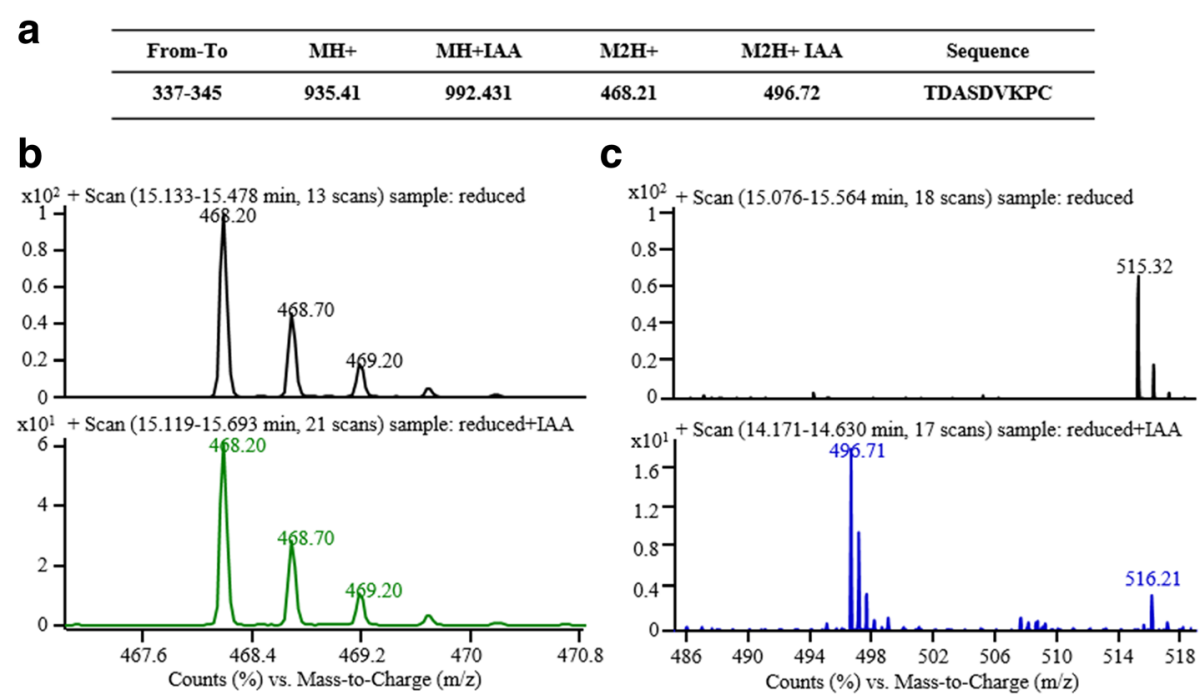

Fig. 3 LC/MS-based peptide characterization method development for reduced $\beta 2$ GPI. The theoretical MWs of the target peptide (TDASDVKPC) in different charge and alkylation form was described (a). The digestion product after reduction and reduction plus alkylation were compared (b \& c). b shows the reduced peptide form of $\mathrm{MH}^{2+}$, while $\mathrm{c}$ shows the alkylated peptide form of $\mathrm{MH}^{2+}$. Especially in Fig. c, alkylated peptide can be characterized only in the reduction plus alkylation sample, which implies that if the cysteine is blocked with GSH, then it will not be alkylated

but a decreased reduced peptide (Fig. 3b \& c, lower). In this way, the method can be used in reduced and GSHblocked protein analysis.

The samples from different conditions of the reduced and GSH-blocked protein analysis step are shown in Fig. 4a. Based on the LC/MS analysis, the reduced and GSH-blocked protein resulted in only a reduced peptide, but the reduced and alkylated protein resulted in only an alkylated peptide. The $\mathrm{M}^{2 \mathrm{H}+}=468.21$ ion chromatography and the peak of the reduced and GSH-blocked protein indicated that Cys326 was reduced by TRX. The $\mathrm{M}^{2 \mathrm{H}+}=496.72$ ion peak for the reduced and alkylated protein proved that the reduced and alkylated Cys326 peptide exist.

\section{Immunoreactivity of reduced $\beta 2 \mathrm{GPI}$}

To further confirm that the reduced $\beta 2$ GPI has maintained its disulfide bridges without disrupting the other domains, an anti-human $\beta 2$ GPI antibody was used for Western blot analysis. The results showed that both oxidized $\beta 2$ GPI and reduced $\beta 2$ GPI can bind mouse anti-human $\beta 2$ GPI antibody (Fig. 5), thus indicating that the reduced $\beta 2$ GPI can still maintain the immunoreactivity of $\beta 2 \mathrm{GPI}$ and, at least, maintains the original structure of domain I.

\section{Reduced $\beta 2$ GPI protects HUVECs from oxidative stress- induced cell death}

To confirm whether reduced $\beta 2$ GPI can maintain its biological activity after GSH blockage, we conducted an
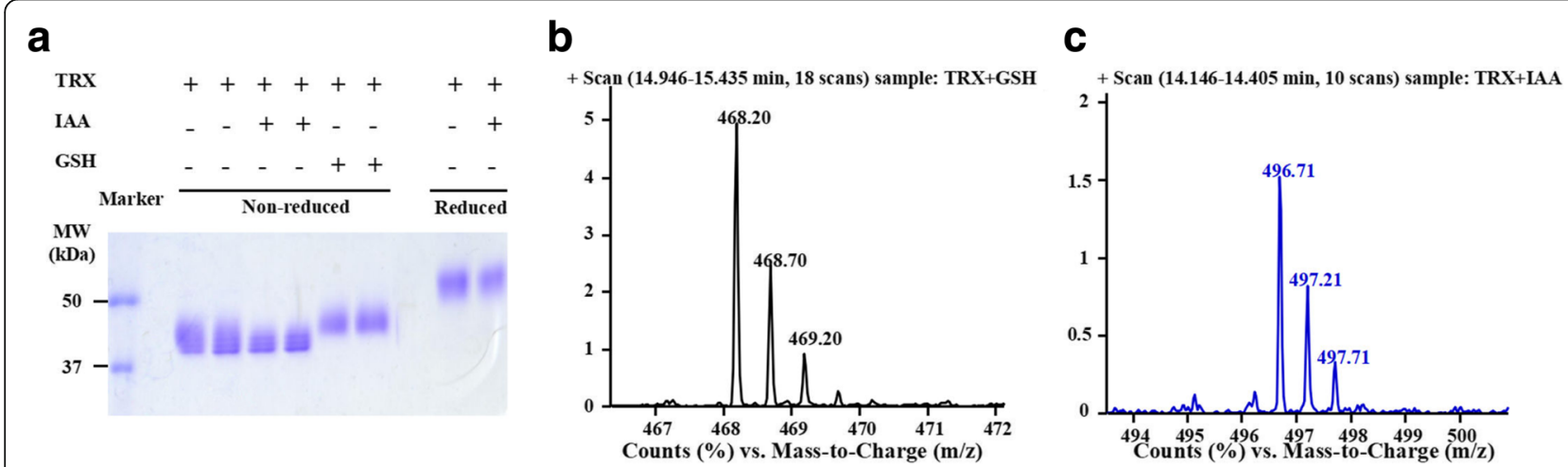

Fig. 4 The final LC/MS characterization of the reduced and GSH-blocked $\beta 2$ GPI. a Reduced $\beta 2$ GPI blocked by GSH showed different MWs non-reduced SDS-PAGE conditions. b The LC/MS ion peak of GSH blocked reduced $\beta 2$ GPI. c The LC/MS ion peak of IAA blocked $\beta 2$ GPI. The sample conditions and the profile comparison on SDS-PAGE was visualized (a). The samples in lane 7 and lane 5 were digested and analysed by LC/MS. The reduced and GSH-blocked $\beta 2 \mathrm{GPI}$ sample shows only the reduced peptide form of $\mathrm{MH}^{2+}(\mathbf{b})$, while the reduced and alkylated $\beta 2 \mathrm{GPI}$ sample shows only the alkylated peptide form of $\mathrm{MH}^{2+}$. These results proved that our reduced and GSH-blocked $\beta 2 \mathrm{GPI}$ was produced in the right form 


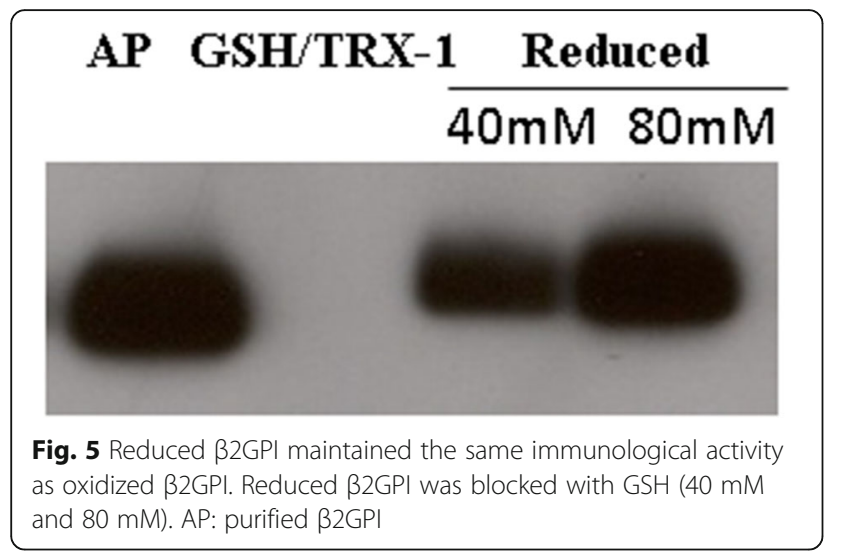

experiment as previously reported [4]. Our results showed that reduced $\beta 2$ GPI can significantly improve the activity as well as the number of living cells (Fig. $6 \mathrm{a}$ and $\mathrm{b}$ ) and reduce apoptosis (Fig. 6c and d) in HUVECs after $\mathrm{H}_{2} \mathrm{O}_{2}$ treatment.

\section{Reduced $\beta 2$ GPI has anti-inflammatory activity in LPS- mediated systemic inflammation}

New evidence has revealed that $\beta 2$ GPI plays an important role in the innate immune response [7-9], and reduced $\beta 2$ GPI can relieve LPS-stimulated inflammation in mice [9]. To assess the anti-inflammatory activity of the reduced $\beta 2 \mathrm{GPI}$ after GSH blockage, an LPSmediated inflammation experiment was performed as reported in our previous study [9]. The results showed that only reduced $\beta 2 \mathrm{GPI}$ could significantly decrease the levels of IL-6, TNF- $\alpha$, MCP-1 and IFN- $\gamma$ in mice serum $6 \mathrm{~h}$ after LPS injection (Fig. 7).

\section{Discussion}

Reduced 32 GPI was first reported by Professor Krilis' team in recent years and was found to be the main form of $\beta 2$ GPI in human plasma $[3,11]$. Increasing evidence indicates that this free thiol $\beta 2$ GPI plays a protective role in vascular diseases [3-5] and could also function as a scavenger protein for LPS to attenuate inflammation $[7,9]$. These new functions of $\beta 2 \mathrm{GPI}$ were attributed to the antioxidative stress and anti-inflammatory activities of the reduced form of $\beta 2$ GPI. However, the mechanism of action of this special form of $\beta 2 \mathrm{GPI}$ is poorly understood. Until now, the successful extraction of reduced $\beta 2 \mathrm{GPI}$ from plasma or serum, which impeded the further study of this special form of $\beta 2$ GPI, had not been accomplished. Therefore, obtaining a stable free thiol $\beta 2$ GPI in vitro is a promising solution. a

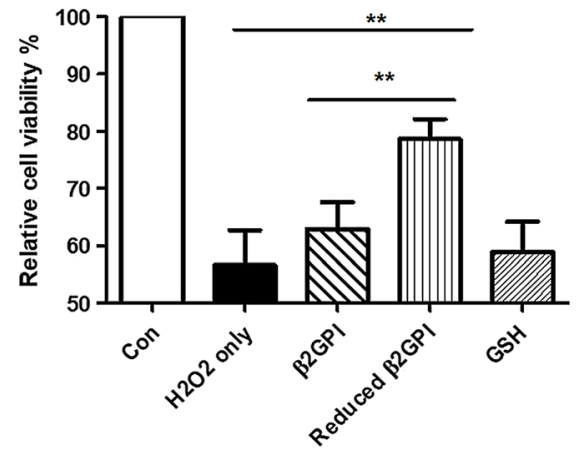

C

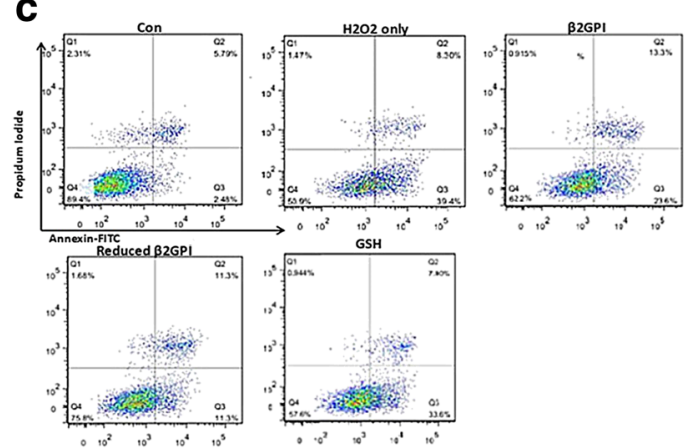

b

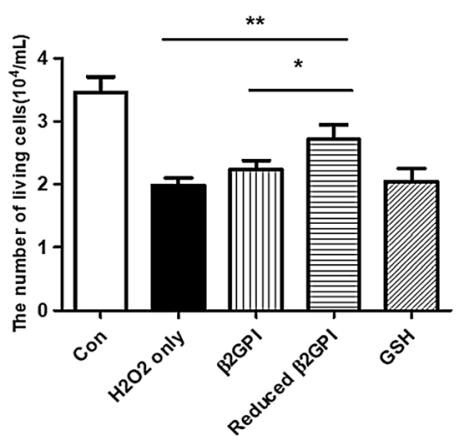

d

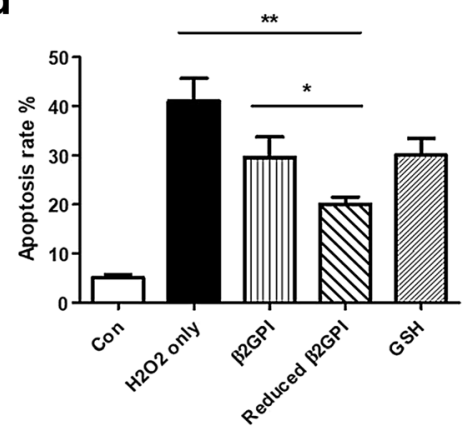

Fig. 6 Reduced $\beta 2$ GPI protected HUVECs from oxidative stress-induced cell death. Reduced $\beta 2$ GPI increased the HUVECs cell viability (a) and cell number (b) upon the $\mathrm{H}_{2} \mathrm{O}_{2}$ treatment. (c) The image of the cell apoptosis by FACS. (d) Reduced $\beta 2 \mathrm{GPI}$ protected HUVECs from apoptosis under $\mathrm{H}_{2} \mathrm{O}_{2}$ treatment. HUVECs incubated with $\beta 2 \mathrm{GPI}(1 \mu \mathrm{M})$ were pretreated with TRX-1 $(1.75 \mu \mathrm{M})+\mathrm{DTT}(35 \mu \mathrm{M})+\mathrm{GSH}(80 \mathrm{mM})$ for $30 \mathrm{~min}$ at $37^{\circ} \mathrm{C}$ and then incubated with $4 \mathrm{mM} \mathrm{H}_{2} \mathrm{O}_{2}$ for $40 \mathrm{~min}$ at $37^{\circ} \mathrm{C}$. No difference was observed $(n=5)$ between $\mathrm{H}_{2} \mathrm{O}_{2}$-only-treated cells and $\beta 2 \mathrm{GPI}$ only or TRX-1 $(1.75 \mu \mathrm{M})+\mathrm{DTT}(35 \mu \mathrm{M})+\mathrm{GSH}(80 \mathrm{mM})$. For all panels, ${ }^{*} P<0.05$ and $* * P<0.001$ 

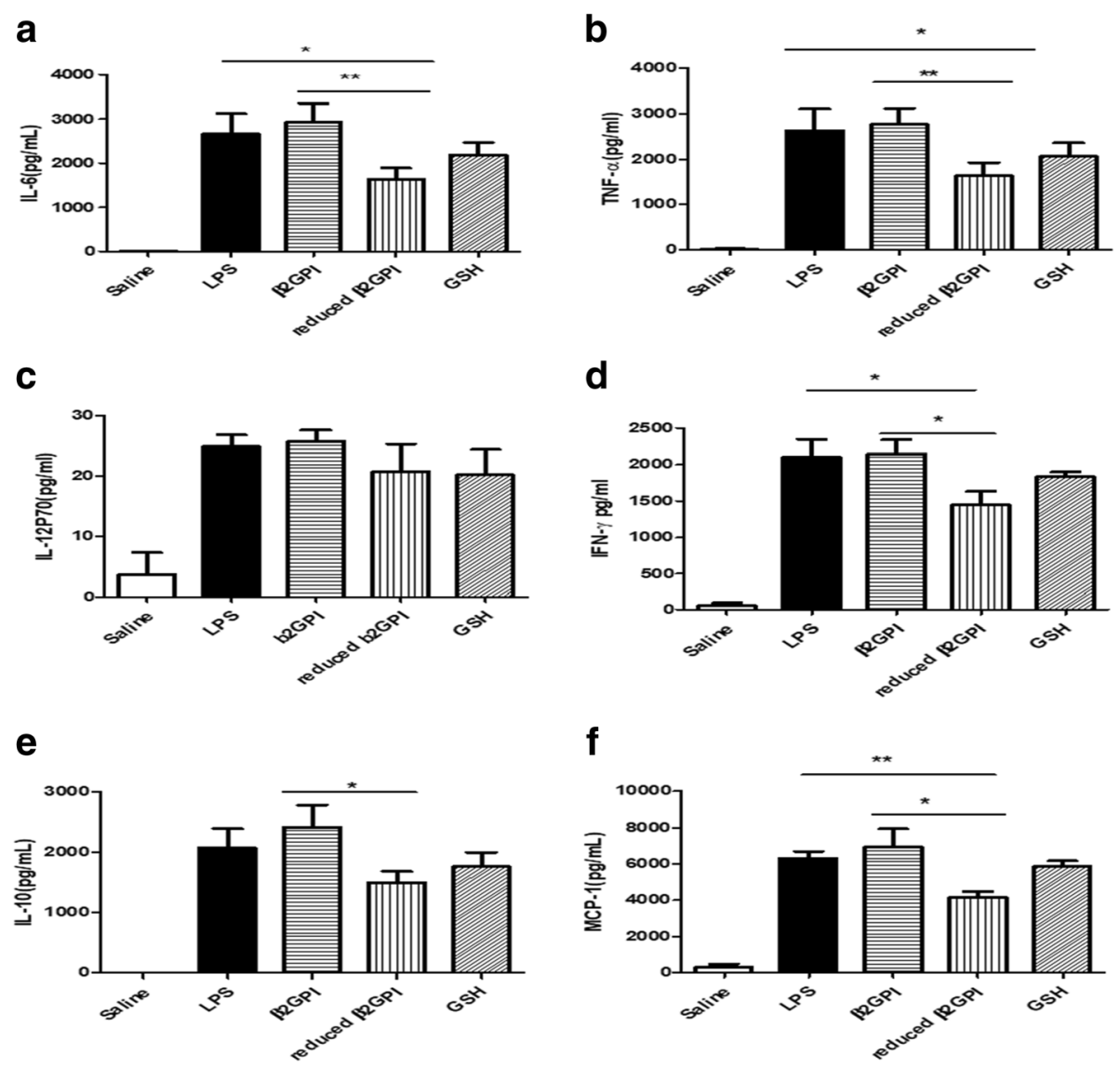

Fig. 7 Reduced $\beta 2$ GPI inhibited LPS-mediated inflammation in mice. The effect of reduced $\beta 2$ GPI on the levels of IL-6 (a), TNF-a (b), IL-12P70 (c), IFN- $\gamma$ (d), IL-10 (e) and MCP-1 (f) in mice serum upon LPS stimulation. Purified plasma $\beta 2$ GPI $(2 \mu \mathrm{M})$ or reduced $\beta 2 \mathrm{GPI}$ with 1 nM LPS were preincubated for $15 \mathrm{~min}$ at $37^{\circ} \mathrm{C}$ before injection into mice at $1 \mu \mathrm{g} / \mathrm{g}$ body weight (gbw) with E. coli LPS (Sigma-Aldrich) in sterile saline or the same volume of saline with TRX-1 $(1.75 \mu \mathrm{M})+\mathrm{DTT}(35 \mu \mathrm{M})+\mathrm{GSH}(80 \mathrm{mM})$ through the tail vein. At $6 \mathrm{~h}$ post injection, mice were euthanized, and approximately $1 \mathrm{ml}$ of blood was collected by cardiac puncture. Serum was collected and the levels of cytokines (IL-6, TNF-a, MCP-1, IFN- $\gamma$, IL-10, IL-12P70) were quantified. Reduced $\beta 2 \mathrm{GPI}$ significantly reduced the levels of IL-6, TNF-a, MCP-1, and IFN- $\gamma$. No difference was observed $(n=5)$ between $\beta 2 \mathrm{GPI}$ only or GSH and LPS. For all panels, ${ }^{*} P<0.05$ and ${ }^{* *} P<0.001$

$\beta 2$ GPI is known to be an abundant plasma protein with a molecular weight of approximately $50 \mathrm{kDa}$, and its concentration in human plasma is approximately $200 \mu \mathrm{g} / \mathrm{mL}$ $[2,18]$. Therefore, the isolation of $\beta 2 \mathrm{GPI}$ from plasma is more economical and more efficient than recombinant protein purification. This study established a simple and effective method to purify $\beta 2$ GPI from human plasma by treating plasma with perchloric acid, followed by a series of chromatography steps, namely, desalting with a G-25 column and purification with an SP HP column, AFheparin HC-650 M column, and S-200 column. This purification procedure increased the yield of $\beta 2$ GPI from human plasma. The final yield of $\beta 2$ GPI was approximately $10 \mathrm{mg}$ from $200 \mathrm{ml}$ plasma. This procedure also yielded a high purity of $98.7 \%$. Thus, this method could effectively isolate $\beta 2 \mathrm{GPI}$ with high purity from human plasma.

To prepare the reduced $\beta 2$ GPI, the DTT-activated oxidoreductase TRX-1 was used to cleave the disulfide bridge in $\beta 2 \mathrm{GPI}$, as previously reported [3]. A large proportion of plasma $\beta 2$ GPI exists in free thiol form because thioredoxin (TRX) is expressed widely in prokaryotic cells and eukaryotic cells. $\beta 2$ GPI is one component of the TRX system, and the other two components are the TRX reductase (TrxR) and reduced nicotinamide adenine dinucleotide phosphate [3]. This system plays an important role in maintaining the stable redox state in vivo. In mammals, three isozymes of TRX exist: TRX-1 (located in the cytoplasm), TRX-2 (located in the mitochondria), and TRX-3 (located specifically in sperm, Sptrx-3) $[19,20]$. The thiol exchange reaction was also reported to occur in $\beta 2 \mathrm{GPI}$, with the help of some reductase systems in platelets [21] or vascular endothelial cells [3]. Therefore, using the TRX system to reduce $\beta 2$ GPI has physiological implications. As such, in the present study, we selected TRX-1 as the reducing agent to simulate the physiological transformation of oxidized $\beta 2 \mathrm{GPI}$ to reduced $\beta 2 \mathrm{GPI}$, as 
previously reported $[3,11]$. LC/MS analysis showed that none of the disulfide bonds in domain I-IV of $\beta 2$ GPI was disrupted and that only the disulfide bond formed by Cys288 and Cys326 in domain V was disrupted, along with the formation of corresponding thiols at the points of Cys288 and Cys326. This result corresponded to the molecular bioinformatics analysis of the $\beta 2 \mathrm{GPI}$ molecular structure that was reported in a previous study [18].

According to the results of molecular bioinformatics analysis, among the 11 disulfide bonds in the molecule, the Cys288-Cys326 disulfide bond in domain V revealed a $-/+$ right-handed hook structure, and TRX-1 specifically interacts with the disulfide bond within this structure $[15,16]$. Furthermore, Cys326 is exposed on the surface of this molecule; thus, this disulfide bond easily interacts with TRX-1. Therefore, the TRX-1 reduction method in vitro is an effective way to produce reduced $\beta 2$ GPI. Other disulfide-reducing agents, such as $\beta$ mercaptoethanol, generally reduces most cysteine residues in a non-selective manner. Our results revealed that the $\beta 2$ GPI sample that reacted with DTT or $\beta$ mercaptoethanol had a slower electrophoresis rate than the sample that reacted with TRX-1. Western blot analysis failed to detect its immunological activity (data not shown). Western blot analysis only detected $\beta 2$ GPI activity in the activated TRX-1-treated samples, which also indicates that the free thiols in DI-DIV of $\beta 2$ GPI were not disrupted. Thus, neither DTT nor $\beta$-mercaptoethanol is able to simulate the physiological thiol conversion reaction in $\beta 2$ GPI. Meanwhile, TRX-1 is not only a physiological reducing reagent but also an effective reducing agent to produce reduced $\beta 2 \mathrm{GPI}$ in vitro.

LC/MS analysis did not detect any free thiols in $\beta 2$ GPI before treatment with TRX-1/DTT in the present study, thus suggesting that the $\beta 2$ GPI extracted from plasma existed in the oxidized form. One important reason is that reduced $\beta 2$ GPI cannot maintain its stability in vitro or under oxidative conditions. Figure 3 shows that reduced $\beta 2 \mathrm{GPI}$, without thiol blockage, was degraded at $37{ }^{\circ} \mathrm{C}$ overnight and was unstable.

In this study, we acquired stable reduced $\beta 2$ GPI in vitro in the following steps: extracting purified $\beta 2$ GPI from plasma, performing the reduction reaction in vitro, and protecting the free thiols of reduced $\beta 2$ GPI using GSH. Figure 3 shows that GSH blockage can stabilize reduced B2GPI compared with cysteamine. GSH is a small physiological molecule that does not cause toxicity and immunogenicity to the human body and could be an ideal thiol blocker for reduced $\beta 2$ GPI.

With the blockage of GSH, reduced $\beta 2 \mathrm{GPI}$ will maintain its immunoreactivity. Western blot analysis showed that both the reduced $\beta 2$ GPI blocked with GSH and oxidized $\beta 2$ GPI could detect the same antibody. This finding indicated the existence of a disulfide bond in domain I and the structural integrity of domain I in reduced $\beta 2$ GPI because the antibody combined with the specific epitope in domain I of $\beta 2$ GPI.

Reduced $\beta 2$ GPI was identified to have anti-oxidative stress and anti-inflammatory activity $[3,9]$. To further verify the biological activity of the reduced $\beta 2 \mathrm{GPI}$ blocked with GSH, we detected its effect on oxidative stress- $\left(\mathrm{H}_{2} \mathrm{O}_{2}\right)$-induced HUVEC cell death and the cytokine levels in LPS-mediated systemic inflammation in mice. The results confirmed that compared with $\beta 2 \mathrm{GPI}$ or GSH, reduced $\beta 2$ GPI had significantly improved activity, reducing apoptosis and decreasing the IL- 6 and TNF- $\alpha$ levels. Therefore, the GSH blocker could not impede the biological activity of reduced $\beta 2 \mathrm{GPI}$, and this activity was independent of GSH.

\section{Conclusion}

We prepared stable reduced $\beta 2$ GPI by TRX-1 deoxidation followed by thiol protection with GSH in vitro. This special form of $\beta 2$ GPI with GSH-blocked free thiols maintained the immunoreactivity and bioactivity of reduced $\beta 2 \mathrm{GPI}$. This study not only provides an effective way to isolate $\beta 2$ GPI from plasma but also shows a simple method to maintain the stability of reduced $\beta 2$ GPI in vitro, which is important to the further study of the physiological function of reduced $\beta 2 \mathrm{GPI}$.

\section{Abbreviations}

B2GPI: $\beta 2$-glycoprotein I; CV: Column volume; DTT: DL-dithiothreitol; GSH: Glutathione; HUVECs: Human umbilical vein endothelial cells; IAA: lodoacetamide; IL-6: Interleukin-6; LPS: Lipopolysaccharide; MAPK: Mitogen-activated protein kinase; MMPs: Matrix metalloproteinase; ox-LDL: Oxidized low density lipoprotein; PDI: Protein disulfide isomerase; Sptrx-3: Sperm-specific TRX-3; TFA: Trifluoroacetic acid; TIMPs: Tissue inhibitors of metalloproteinases; TrxR: TRX reductase

\section{Acknowledgements}

Not applicable.

\section{Funding}

This work was financially supported by the National Natural Science Foundation of China (No. 81600643), the Tianjin Health Industry Key Research Projects (No. 15KG101), Tianjin Science and Technology Support Project (NO. 17JCYBJC27000). There is no conflict of interest to declare.

\section{Availability of data and materials}

Data sharing is not applicable to this article, as no datasets were generated or analysed during the current study.

\section{Authors' contributions}

SJZ, ML, JTZ, SHL, XL, RZ and HYL performed the experiments, and SJZ drafted the manuscript. PY and SJZ designed the study. PY coordinated the experiments and helped to draft the manuscript. All authors read and approved the final manuscript.

\section{Ethics approval and consent to participate}

All procedures were performed in accordance with the institutional guidelines for human and animal research and were approved by the Animal Care and Use Committee of Metabolic Diseases Hospital of Tianjin Medical University, Tianjin, China. 


\section{Competing interests}

The authors declare that they have no competing interests.

\section{Publisher's Note}

Springer Nature remains neutral with regard to jurisdictional claims in published maps and institutional affiliations.

Received: 14 April 2017 Accepted: 28 August 2017

Published online: 13 September 2017

\section{References}

1. Miyakis S, Giannakopoulos B, Krilis SA. Beta 2 glycoprotein I-function in health and disease. Thromb Res. 2004;114(5-6):335-46.

2. Giannakopoulos B, Krilis SA. The pathogenesis of the antiphospholipid syndrome. N Engl J Med. 2013;368(11):1033-44.

3. Ioannou Y, Zhang JY, Passam FH, Rahgozar S, Qi JC, Giannakopoulos B, et al. Naturally occurring free thiols within beta 2-glycoprotein I in vivo: nitrosylation, redox modification by endothelial cells, and regulation of oxidative stress-induced cell injury. Blood. 2010;116(11):1961-70.

4. Wang WL, Meng ZX, Zhou SJ, Li CJ, Chen R, Lv L, et al. Reduced beta2glycoprotein I protects macrophages from ox-LDL-induced foam cell formation and cell apoptosis. Lipids Health Dis. 2013;12:174

5. Ma J, Zhang JY, Liu Y, DM Y, YP. Redox status Of $\beta 2 \mathrm{GPI}$ in different stages of diabetic Angiopathy. Dis Markers. 2016;2016:8246839.

6. Yu P, Passam FH, Yu DM, Denyer G, Krilis SA. Beta2-glycoprotein I inhibits vascular endothelial growth factor and basic fibroblast growth factor induced angiogenesis through its amino terminal domain. J Thromb Haemost. 2008;6(7):1215-23.

7. Agar C, de Groot PG, Morgelin M, Monk SD, van Os G, Levels JH, et al. Beta(2)-glycoprotein I: a novel component of innate immunity. Blood. 2011; 117(25):6939-47.

8. Gries A, Prassl R, Fukuoka S, Rossle M, Kaconis Y, Heinbockel L, et al. Biophysical analysis of the interaction of the serum protein human beta2GPI with bacterial lipopolysaccharide. FEBS Open Bio. 2014;4:432-40.

9. Zhou S, Chen G, Qi M, El-Assaad F, Wang Y, Dong S, et al. Gram negative bacterial inflammation ameliorated by the plasma protein Beta 2glycoprotein I. Sci Rep. 2016;6:33656.

10. Passam FH, Rahgozar S, Qi M, Raftery MJ, Wong JWH, Tanaka K, et al. Beta 2 glycoprotein I is a substrate of thiol oxidoreductases. Blood. 2010; 116(11):1995.

11. Passam FH, Rahgozar S, Qi M, Raftery MJ, Wong JWH, Tanaka K, et al. Redox control of $\beta(2)$-glycoprotein I-von Willebrand factor interaction by thioredoxin-1. J Thromb Haemost. 2010;8(8):1754-62.

12. Xu J, Wang $P$, Wang $T$, Wang $M$, Chen $S$, Yu $P$, et al. Effects of reduced $\beta(2)$ glycoprotein I on the expression of aortic matrix metalloproteinases and tissue inhibitor matrix metalloproteinases in diabetic mice. BMC Cardiovasc Disord. 2014;14:114.

13. Liu H, Zhou S, Denyer G, Meng Z, Chen R, Lv L, et al. Reduced beta2glycoprotein capital I, Ukrainian inhibits hypoxiainduced retina angiogenesis in neonatal mice through the vascular endothelial growth factor pathway. Mol Med Rep. 2015;11(2):1025-30.

14. Qi M, Abdelatti M, Krilis M, Madigan MC, Weaver J, Guymer RH, et al. Do Beta 2-glycoprotein I disulfide bonds protect the human retina in the setting of age-related macular degeneration? Antioxid Redox Signal. 2016;24(1):32-8

15. Szigeti M, Bondar J, Gjerde D, Keresztessy Z, Szekrenyes A, Guttman A. Rapid $\mathrm{N}$-glycan release from glycoproteins using immobilized PNGase $F$ microcolumns. J Chromatogr B. 2016:1032:139-43.

16. Fujii N, Sakaue H, Sasaki H, Fujii NA. Rapid, comprehensive liquid chromatography-mass spectrometry (LC-MS)-based survey of the asp isomers in crystallins from human cataract lenses. J Biol Chem. 2012; 287(47):39992-40002.

17. Abeykoon AH, Chao CC, Wang G, Gucek M, Yang DC, Ching WM. Two protein lysine methyltransferases methylate outer membrane protein $B$ from rickettsia. J Bacteriol. 2012;194(23):6410-8.

18. Krilis SA, Giannakopoulos B. Laboratory methods to detect antiphospholipid antibodies. ASH Education Program Book. 2014;2014(1):321-8.

19. Cunningham GM, Roman MG, Flores LC, Hubbard GB, Salmon AB, Zhang $Y$, et al. The paradoxical role of thioredoxin on oxidative stress and aging. Arch Biochem Biophys. 2015;576:32-8.
20. Buckman C, Ozanon C, Qiu J, Sutovsky M, Carafa JA, Rawe VY, et al. Semen levels of spermatid-specific thioredoxin-3 correlate with pregnancy rates in ART couples. PLoS One. 2013;8(5):e61000.

21. Passam FH, Rahgozar S, Qi M, Raftery MJ, Wong JWH, Tanaka K, loannou Y, Zhang JY, Gemmell R, Qi JC, Giannakopoulos B, Hughes WE, Hogg PJ, Krilis SA. Redox control of $\beta 2$-glycoprotein I-von Willebrand factor interaction by thioredoxin-1. J Thromb Haemost. 2010;8(8):1754-62.

\section{Submit your next manuscript to BioMed Central and we will help you at every step:}

- We accept pre-submission inquiries

- Our selector tool helps you to find the most relevant journal

- We provide round the clock customer support

- Convenient online submission

- Thorough peer review

- Inclusion in PubMed and all major indexing services

- Maximum visibility for your research

Submit your manuscript at www.biomedcentral.com/submit
Biomed Central 